\title{
Decentralization as a Commitment to Rise Public Services and Improve Quality of Rural Life in Ethiopia: A Case Study
}

\author{
Sintayoh Fissha \\ Grant MacEwan University Sessional Instructor, \\ Department of Economics, Edmonton, Alberta, T5J 2P2, Canada \\ E-mail: sintayoh@yahoo.com or geberegziabhers@macewan.ca
}

Meheret Brehanu

College of Business and Economics, Mekelle University, Mekelle, Ethiopia

Received: Sep. 11, 2017 Accepted: Nov. 20, 2017 Online published: Dec. 10, 2017 doi:10.5296/jpag.v7i4.12276 URL: https://doi.org/10.5296/jpag.v7i4.12276

\begin{abstract}
The main objective of this study is to examine the implication of decentralization in rural areas of Ethiopia: Case of Tigray. The study aims to discuss effect of decentralization on service delivery and improving quality of life of some Weredas of rural Tigray focusing on education, health, and water point.

To conduct this studies both; qualitative (phenomenological approach), and quantitative (household survey, and wereda level local government expenditure) data were used. Results indicate the positive effect of fiscal decentralization on service delivery. Likewise decentralization effect on improving quality of life is progressing but it is still minimal. Comparing with pre decentralization there are positive changes but there is a considerable differences on its corollary. The possible reason for differences to occur could be variations in agro-ecological condition, location or space, and capability of the decision makers.
\end{abstract}

Keywords: decentralization, service expansion, and quality of life

\section{Introduction}

Attention to decentralization in developing countries was initially motivated by political 
reasons like the South Africa (Ahmad, 1998), Moldova (IMF, 1999), and Philippines (Eaton, 2001) (D2). But, now days there are more countries experimenting with decentralization, and they contemplated it as an exit to many different kinds of problems (James Manor1999, vii cited Jumadi, M. Pudjiharjo, Maski, G., Khusaini, M. 2013 Decentheor).

The meanings of decentralization differ from scholars to scholars. In its basic definition, it entails the transfer of responsibility and authority to field units, and the sharing of central government power with other institutions, (Turner and Mulme, 1997, Schneider. A, 2003, Tegengn and Kassaahun, 2004), Ndegwa, 2002).

The Ethiopian government seem to understand the good will of power devaluation to the local level as a panacea to all kinds of economic and political problems (Jumadi, M. Pudjiharjo, Maski, G., Khusaini, M. 2013). At present many believe decentralization in Ethiopia (both; political and fiscal) reduced the legitimacy of the central government's action, created an environment that favors reducing the size of public sector, and granted power to both the market and local jurisdictions. But, these groups failed to answer the question of: under which circumstance does decentralization enhanced development?

Even G. Falleti (2005, P.329) noted how even definitions (like the one above) poses important restrictions. In his writing he stated: first, it is conceived as a process of public policy reforms and not as a description of the political systems. Second, lower levels of government are not the main planner rather they are recipients of the transferred responsibilities, resources, or authority. Third, because it is a process of state reform, it sequential, and a transition to a different type of state necessarily implies the commencement of a new system.

\subsection{The Rationale of this Study}

Many disregard pre-1991 regimes instances of decentralization, date decentralization in Ethiopia to the establishment of Transitional Government of Ethiopia in 1991, which became as an institutional tool since then (Ayele, T. 2011, Tegegne and Kassahun, 2004).

The decentralization drive in Ethiopia has proceeded in two phases. The first wave of decentralization (1991-2001) centered on creating and empowering National/Regional Governments and hence was termed as mid-level decentralization (Yigremew 2001).

Generally the Ethiopian government adopt decentralization policy for the same reason as others did, it was essentially to ensure the following (OXFAM, 2005):

(a) participation of citizens in state affairs (b) empowerment of citizens especially women

(c) accountability of duty bearers to people citizen (d) transparency in system of decisions

(e) maintenance of peaceful conditions and (f) efficient and equitable allocation as well as efficient utilization of the country's resources including efficient quality of resources including efficient delivery of quality service to the poor.

However, there were debates on what has been gained (LDI, 2013) owing to the shortcomings of the first wave of decentralization. Then, District Level decentralization Program (DLDP) was launched in Tigray in 2001. The DLDP encompasses all the three major aspects of decentralization namely political, administrative and fiscal. This initiative 
was following the long tradition of theoretical analyses that verifies decentralization effects economic growth of the local (Oates, 1993; Bird, 1993; and Gramlich, 1993). However, in Ethiopia the decentralization system was challenged by some technical and procedural related paucity. These include:

First, Woredas are empowered to plan for their rationalization but are also hierarchy subordinate bodies to the Regional Government. Second, the role of local government is very limited because of inadequate budget, and second limited skill, which could effect to a negative impact on regional economic growth (Martinez and McNab, 2001; Rondinelli, Cheema and Nellis (1983); and Smoke, P. 2001).

In Ethiopia diverse studies (Ayele, 2011, Sintayoh F. Meheret, B. and and Mathijs, E. 2013) also shows the challenges. In the study woredas ${ }^{1}$ introduction of market oriented economic policy helped citizens to appreciate economic values and people are working hard to increase their income. But, the opportunities created are not sufficient enough to have a market that organizes its economic activity. Fiscal decentralization policies designed poorly created a stimulus for local governments to perform Dangan spending, less responsible and sustainable (Phillips, 1997).

A study conducted by Snyder (2001) stated: under this system Ethiopia never remain at national level, focuses are on small administrative units. Politicians shifted the locus of their analyses from the national to the sub national levels. But in practice resource allocation, planning and decision making is not fully decentralized as sub national are still the main implementers of the country development policy. Our observation during the focus group discussion and interview also revealed the following problems.

First, the problem related to resource allocation by the center, which is in the form of block grant scheme that neither regions nor weredas are receiving their total budget in the form of block grant. ${ }^{2}$ Second, the technical skill and capacity of werda administrators is not competitive. Third, regions as well as weredas are affected by promises that are supposed to come from different donors (which are really part of the budget) but remain as pledged. Given these limitations there are general arguments on its optimal effect, its corollary and impact on poverty. But there is no specific study conducted in the way that it shows its actual ramification. To discuss the effect of fiscal decentralization on service delivery in Ethiopia this paper employed sequential theory of decentralization (G. Falleti, T., 2005). ${ }^{3}$

To develop the argument this paper is organized into three sections. The first section defines the main concept of decentralization, rationale of the study, theoretical framework, research question, and hypothesis. Section two focuses on conceptual framework, evidences of

\footnotetext{
${ }^{1}$ Atsebi, Wekero, Hagereselam, and Tanka'abergele

${ }^{2}$ Block grant is not fully established, there are several non-block grants transferred from different perspectives, which are becoming facts for corruption and inappropriate utilization of public resources.

${ }^{3}$ A sequential theory of decentralization has three main characteristics: a) it defines decentralization as a process; b) it takes into account the territorial interests of bargaining actors; and c) by incorporating policy feedback effects, it provides a dynamic account of institutional evolution.
} 
decentralization and public utilities outcomes in Ethiopia, a conceptual approach to measuring quality of life using objective indicator, and instrument and methodology of the study. Section three presents the main result followed by conclusion.

\subsection{Research Questions}

Unlike the political scientists who draw from the liberal tradition that argues decentralization helps to deepen and consolidate democracy by devolving power to local governments (Diamond and Tsalik 1999). Economists mainly draw their ideas from a market theory of local expenditures. They argue that decentralization helps to improve resource allocation through better knowledge of local preferences and competition among localities (Oates 1972). This paper is aliened to this economic theory and attempted was to investigate the link between decentralization, service expansion, and its impact.

It is based on this theory this study tried to answer the following questions.

- Does fiscal decentralization enhanced service expansion?

- To what extent does service expansion improve the quality of life in a way that changes the livelihood (welfare) of the individuals?

\section{Evidences of Decentralization and Public Utilities Outcomes in Ethiopia}

Earlier studies on Ethiopia and elsewhere shows about decentralization effect but most of them conducted at the regional level are too general, and they revealed the beneficial effect. This part of the paper tried to looked at the previous reviews; pulled key issues together in very specific contexts to build the argument.

WB (2013) study shows the implication of decentralization in enhancing spending efficiency through creating of better capacity, more transparency, and more citizen accountability in Ethiopia.

The little progresses attained in terms of social service provision in Ethiopia after introduction of fiscal decentralization was also noted by Ayele, Z. (20110). Ayle used the report compiled by United Nations Development Program (2010) and it reveals the implication of decentralization on primary education, health, and agricultural extension expansions.

Jumadi, M. Pudjiharjo, Maski, G., Khusaini, M. (2013)- used panel data across districts and cities in East Java Province, which consists of 29 districts and 9 cities identified the effect of fiscal decentralization on human development, physical development, and input factors on economic growth. Result shows significant and positive effect between fiscal decentralization on Human Development.

Mogues, T. et al. (2009), and Von Braun, J., and Grote, U. (2000), investigated effect of decentralization on specific public amenities, access to safe drinking water in northern Ethiopia. The paper was conducted based on qualitative and quantitative surveys on rural public services. Finding indicates little change, but poor quality water supply is affecting the lives of all rural households. Likewise women are highly dissatisfied with the governance of 
water.

\subsection{Conceptual Framework}

The drive to decentralization and devolution of power to the local and regional entities has strengthened the rationale for regional and local development strategies and policies Asfaw, A., Frohberg, K., K.S. James and Jütting, J. (2004). Tte conceptual diagram below indicates the possible facts for any of the positive or negative outcomes.

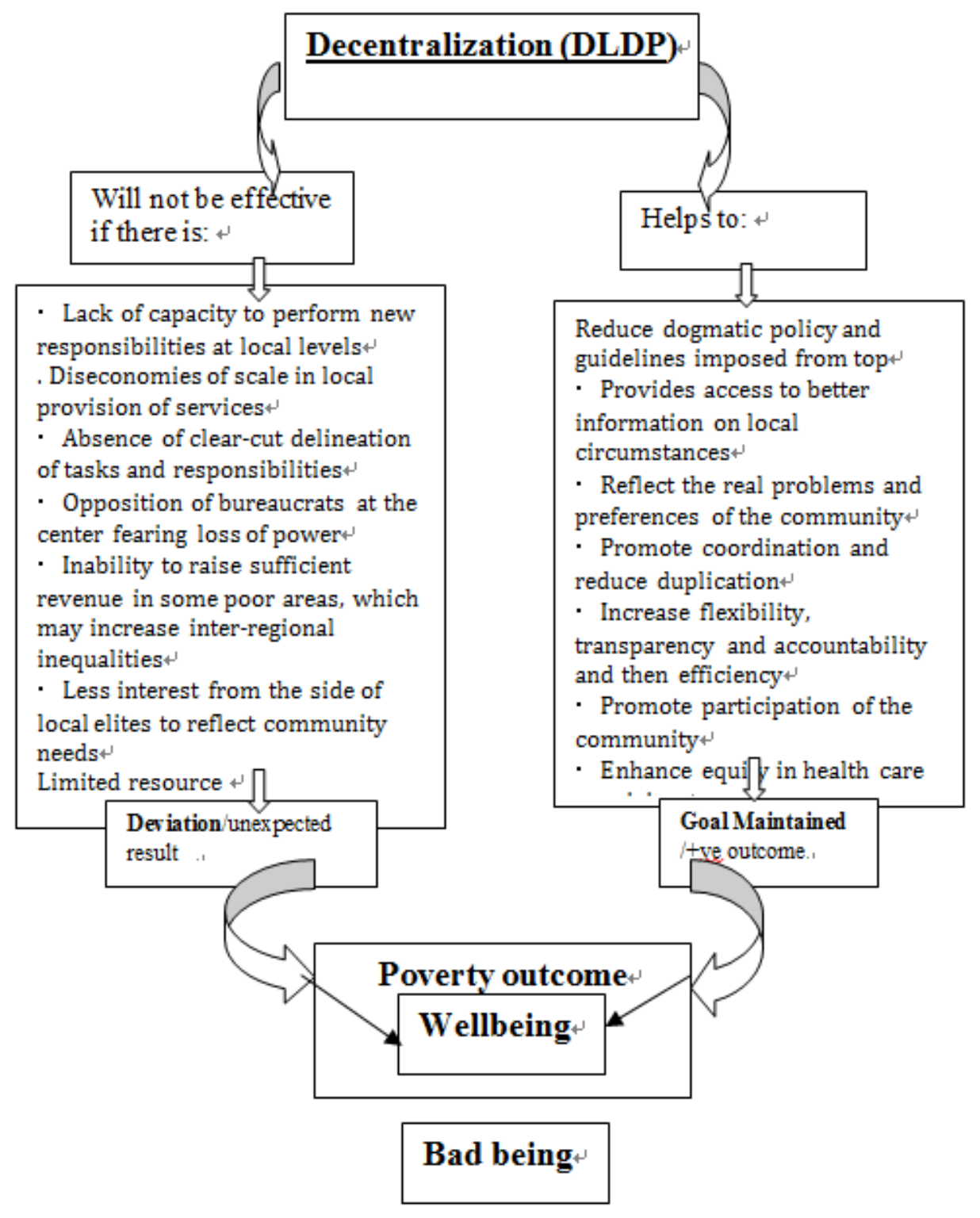

Figure1. Conceptual framework (model) that indicates effect of decentralization (The Model)

The fundamental objective of decentralized development cooperation is "to ensure 'better' development prospects but not always (Hertogs, 1992:2 cited in Tewodros, 2005:52). The above figure presents the advantages of political and fiscal decentralization and its effect in enhancing smooth and efficient running of public affairs that effect to development. 
Better provision of public services is expected to have much wider opportunity in improving skill and capacity that contributes improvement in livelihood which is directly correlated to improvement in activities, assets and entitlement of the community (Tewdros, 2005). Following community participation helps to attain diverse local development initiatives. Because local knowledge and their participation increase efficiency and effectiveness of development programs, enhanced local capacity, and it enabled to achieve objectives of improved livelihoods of the poor (UNDP, 1999).

Locals participation in economic, political and social affairs results to have better development. "In localities where enabling environments for the participation of the community and community based organizations in particular creates, cetieris paribus, it is likely to find the performance of local development programs in a better position than localities where this is not the case."(Tewdros, 2005: p53).

A study conducted by the World Bank suggests the advantage of enabling lower level (local) government (World Bank, 2004), and this is the approach the Ethiopian government is following believing that development own by localities and implemented in collaboration with the community is effective and sustainable. Therefore, it is imperative to see how district level of decentralization (DLDP) effect to the over all local progresses. The conceptual framework (model) above provides the summary of arguments cited in the literature in favor of decentralization when principles are implemented appropriately, and presents the following links.

First, it is argued that a decentralized system, by reducing 'dogmatic policy and guidelines imposed from a center' assists to have access to better information on local circumstances, helps to make rational and flexible decisions that reflect the real problems and preferences of the population, which improves livelihood (wellbeing).

Second, decentralization passes responsibility and accountability to local bodies. This makes local governments work efficiently, flexibly, and creatively by mobilizing all the available resources in their localities to fulfill the targets. Their close relation with the local people enables them to know the local problems and needs, and they are 'therefore in a better position to establish the right priorities than a central (or regional) government far away' (Netherlands Ministry of Foreign Affairs, 2002:5; World Bank, 2004).

Third, decentralization is expected to enhance the participation of local communities in development decisions. It's expected to create an environment for decision makers to have up-to-date information about the preferences and problems of the local people, an effective channel for the people to express their wants and priorities, and a motivating environment for the local decision makers to respond to the local needs quickly and effectively (Khaleghian, 2003).

Our arguments related to decentralization system in Ethiopia is based on this model, focusing on locals' participation in development has led to the slight improvement of wellbeing (following the ceteris paribus). The major limitations are related to: locals are mainly implementers than designers of development, lack of skill and capacity, availability of limited 
resources, and lack of commitment and dedication.

\subsection{Instruments and Methodology of the Study}

\subsubsection{Selection of Study Weredas}

The weredas, Wekero, Atsebi, Tankuabergele, and Hagereselam here after would be denoted as the study woredas were selected considering their ecological condition, their institutional performance, and spatial location. First, they were selected because all these areas are within the boundaries of Giba catchment where the socio-economic project ${ }^{4}$ was operated. Second, their administration performance (considering their strength and/or weakness).

\subsubsection{Sampling}

To conduct this study multistage random sampling technique was used. Sampling of the respondents started from preparing the list of Tabias. ${ }^{5}$ Then from each woreda a proportional sample size was used following a normative approach. The selection of equal sample size from each study woreda was to make appropriate comparison, while selection made the following steps were used.

\subsubsection{Data Analysis}

Once data has been collected two method of analysis such as simple descriptive statistics, (percentage, table, ratio) and ANOVA was used.

ANOVA, a statistical technique invented by R.A Fisher $(1925)^{6}$. ANOVA is one factor model; it assumes that the mean of a variable depends only on one factor, namely the sample from which the observation is taken. For a simple one-way MANOVA, the data set should have one independent variable (grouping variable) and at least two dependent variables. If the model is a type in which it is assumed that two factor determines the mean value of a variable it is called two-factor analysis of variance, two ways MANOVA (Chatfield, 1995). In such cases variable to be observed can be thought of as being arranged in a rectangular array, and the mean value of a specified variable depends on both the row and the column in which it is located. ${ }^{7}$ For a simple one-way MANOVA, the data set should have one independent variable (grouping variable) and at least two dependent variables.

In both cases (both models considered) it is assumed that the data are normally distributed with the same variance $\sigma^{2}$. The analysis of variance approach for testing a null hypothesis HO concerning multiple parameters is based on driving two estimator of the common

\footnotetext{
${ }^{4}$ IUC Project.

${ }^{5}$ Smallest administrative unit.

${ }^{6}$ ANOVA was developed by R.A. Fisher in the mid of 1920s', and become widely known after being included in Fisher's 1925 book Statistical Methods for Research Works, cited in Efron, B. 1998, Journal of Statistical Science, 13(2).

${ }^{7}$ Using two ways ANOVA it is possible to show how to estimate the mean values and test the hypothesis that a specified factor does not affect the mean.
} 
variance $\sigma^{2}$. The first estimator is valid estimator of $\sigma^{2}$ whether the null hypothesis is true or not, while the second one is a valid estimator only when $\mathrm{H} 0$ is true.

In addition when $\mathrm{H}_{0}$ is not true, this latter estimator will over estimate $\mathrm{H}_{0}$, in that estimator will tend to exceed it. Since the two estimators should be close to each other when $\mathrm{H}_{0}$ is true, the second estimator should tend to be larger than the first. When $\mathrm{H}_{0}$ is not true, it is natural to reject $\mathrm{H}_{0}$ when the second estimator is significantly larger than the first.

In this study the dependent and independent variable are more than two, and this was one reason why MANOVA was used (the model has more than two dependent and independent variables). These two independent variable are generated as a result of categorizing respondents based on space (type of woreda) and responsibility.

Where the first subscript refers to the group and the second subscript refers to the variable number. Given this categorization in this study MANOVA is preferable to multiple ANOVAs (or regressions with dummy variables) because:

- Multiple ANOVA/OLS runs can capitalize on chance. For example, if you have 20 dependent variables, you expect $\mathrm{X}$ to have a "significant" effect on one of them if $\alpha=0.05$. MANOVA does a global test of whether group means differ for any of the variables.

- ANOVA/OLS ignore the inter correlations between the independent variables (IVs). Because MANOVA takes them into account, it can provide a more powerful statistical test.

MANOVA uses more information about the data than ANOVA does.

Another common use of MANOVA is it can be applied in repeated measures of design, where the same variable is measured at different points in time (J. Faraway, 2002). By applying this method this study tried to answer the above stated research questions.

\section{Result and Dissuasions}

\subsection{Result and Discussion Based on the Content Analysis}

Assessing the impact of decentralization on poverty reduction is so complex; can't be quantified easily. This complicates the matters for any comprehensive evaluation of optimal decentralization. However, the subsequent pages discuss the implication of fiscal decentralization (DLDP) on locals' participation in development considering the nature of the topic, and taking the well-defined situations into account. .

Service expansion is directly correlated with sectorial development and is provided by different agencies. ${ }^{8}$ The benefits of decentralization in relation to service delivery are usually underpinned by theorists (Steinich, 2000). ${ }^{9}$

\footnotetext{
${ }^{8}$ Its defined as accesses to basic developmental goods or services available to citizens that contribute to human needs or development.

${ }^{9}$ More relevant to local needs( being clear to the people offers the possibility to express needs, increase the responsiveness of personnel, increase the peoples motivation to participate in the implementation of services); More flexible ( being closer to problems, more autonomous in reaction,
} 
In the woreda where this study was conducted decentralization enhanced citizens participation on power politics to some extent. Consequently, development is progressing which effect to fair resource allocation, and service delivery (Ahmed et al. 2005; Shah and Thompson 2004). Service delivery basically refers to the systematic arrangements of activities in service institution with the objective of fulfilling the needs and expectation of service users and other stakeholders use the optimum use of resource (Tesfaye, 2006).

Decentralization created competition among the small administrative units and proximity of local governments. The transfer of development plan responsibilities from the center to the localities helped development strategies to focus on pro-poor choices of investment. This allows citizens more influence over local officials, enhanced competition among local governments, and improves accountability among others. ${ }^{10}$

Moreover decentralization granted self decision making for economic and political agendas. Now day's administrative unit (study woreda) are having the autonomy to decide on matters of economic resource, administer and control of their budget. Their confidences on these matters and their roles in provision public centers have grown much.

However, progresses related to service development was not followed by rising of regional revenues and service qualities. This shows the gap regarding implementation decentralization modalities, that it's not proper. Local governments has not always been effective if commensurate revenue assignments are not sufficient, access to financial markets are inadequate, and necessary administrative capacity on the part of local authorities are absent. ${ }^{11}$

Focus group discussion, and data collected and analyzed reveals the expansion of public amenities (education, health, water point, and road) but only is not a sufficient criteria. For public service impact on wellbeing to be positive first, the quality of the services provided matters, and second the already achievements should be more sustainable but not in this case.

Last, even though having decentralized government system lead to information advantages about the development problems the public services required in the localities, its flexibility in adapting to locals' need, and preferences still requires more institutional change (Informants view). Fiscal decentralization that it can successfully take place only when certain conditions are fulfilled (Tanzi, 2000).

\subsection{Analysis Result Based on Data}

The previous paragraph presented show decentralization helped but also points on the problem, which are complex and are less recognized. A descriptive summery of the effects of

gaining feedback due to participation mechanisms); More innovative (due to more limited extent of consequences of "wrong" decisions, multiplication of learning centers, competition between local communities); Cheaper (due to the identity of payers and clients, thus preventing locally collected taxes to be diverted to higher levels).

${ }^{10}$ During the focus group discussion and key informant interview most government officials submit that their performance is lower and is due to lack of competitive skill.

${ }^{11}$ All informants acknowledged the advantages of decentralized system to rehabilitate environment, which is best experience in the region, which become an instance to other regions. 
fiscal decentralization on services delivery in the study woredas' is presented below. The data was from the interviews conducted, and data compiled form the reports (quarterly, semi annual and annual reports) at each woreda level.

Finding reveals in Atsebi in 2010 people access to safe drinking water and its coverage to rural areas was 73. Compared with 1991 the coverage has increased by $72.9 \%$ (Woreda Report, 2010).

Likewise access to education indicates the same trend, confirmed by the expansion of educational centers, and increasing number of teachers at different woreda level. In 2010 there were 48 school center (increased from 0 in 1991 to 48 in 2010), 3100 enrolled students, and 367 teachers (with the training level of TTI (367), diploma (225), and degree (69)). The increasing number of enrollments, decreasing ratio of attrition was mentioned as evidence about the achievements. Despite these progresses researchers (we) had also noticed challenges like schools are not equipped with the necessary manpower and materials that could create competitive students.

In addition there are similar progresses related to health; health centers, health cadres, and health development agents. In 2010, in the wereda of the total population 58,015 only $4 \%$ has access to health services, which is relatively higher than the past. This is still debatable as there are some who argue stating: all this is not effect of decentralization but it's the health package (strategy) that assisted to attain this target. However, we have noticed the implementing of decentralization complemented by institutional related rules assisted to create individuals that lobbies to the government. Decentralization helped to bring divided groups into a formal, rule-bound bargaining process that puts both administrative and communities on the same path. Confirms state development and state unity are playing a role to minimize state inequalities. Which needs to be strengthening.

In addition the total road constructed from the year 2002 to 2010 is $700 \mathrm{~km}$. Construction of road is enhancing market, and creates opportunities for rural farmers; According to the informants view decentralization also serve as a gizmo to create cooperatives. This is helping first it build team sprit and team work, and second it assisted farmers to adopt technology and application of better farming strategies.

Like that of Atsebi, in wekero the report compiled in 2010 indicates there were an expansion of public services like education, health, public road, water and electricity facilities.

Over all coverage of social services such as education, health, and water was $100 \%, 85 \%$, and $75 \%$ (Wereda level compiled report). On the other hand service related to road has shown progress but was extremely poor. Between 2001 to 2010 in the Woreda on average primary education first cycle, and primary education second cycle has increased by 11.81 and 17.57 percent respectively. In addition secondary education grew on average by 18.24 percent.

Similar to keleteawelaelo and Atsebi health posts $^{12}$ in Hageresleam has shown wider

\footnotetext{
${ }^{12}$ Health posts are one of the satellite facility focused services provision of a primary care unit. It is lead by health extension workers. One health post has 2 health extension workers.
} 
coverage. Over the last eight years it increased on average 9.7 percent. Clinics are growing on average by 57.14 percent but number of hospitals didn't change. Increasing number of health posts resulted in decreasing child and maternal mortality. The total number of reduction of maternal mortality in Hageresealm shows a growth rate of 108.33 percent over the last two years. Over the last five years the total number of child mortality had decreased at an increasing rate, it decreased by 12 percent $r$. Likewise drinking water in the last nine years (2001 to 2010) on average raised by 31.94 percent.

Unlike in other woredas in Tankuaabergle getting the relevant data was hard. Comparison based on the existed data reveals progresses in Tankuaabergle is very poor though there are little changes. In this woreda decentralization did not managed to reverse the dated back public service shortages. Similar to other woredas public services such as education, health, road, and water point has shown minimal improvement but the dissatisfaction of the communities living in the woreda is high though they said its better compared with that of the past (2010)

From what is reported we also noticed major difference about their level of satisfaction between men and women, and also between the communities and the administrators. Unlike the communities the administrators extremely exaggerate the effect of decentralization and sometimes failed even to mention the existed challenges. They tried to veil its impact by stating the positive gains.

In all the study woredas participants were highly dissatisfied with the level of management and administration provided. They mentioned about the late response to conflicts, discrimination of people (based on nepotism and networking), and lack of good governance. A majority of the community tried to express their view about governance comparing pre 1991 period (when they were informally administered by TPLF) were participation of community in creating good governance was cornerstone which is affected by a growing apathy lately.

Issues pertinent to the quality of services are still a major concern. This led citizens to quest about the link between the region and woredas resource utilization and management, planning and budget allocation. Small administrative regions have power; has the authority to implement development plans, and coordination of diverse development strategies. But, resource-wise they are still dependent on the amount of resource that comes from the center and their revenue rising power is still lower than what its expected. Decentralization has become a tool for deflating secessionist tendencies but budget is still controlled by the central government. From the discussion and the data analysis we have learned that decentralization failed to minimize the problem of regional inequalities. The levels of inequality in between the regions and among the woredas are still the same if not worsening because there is no specific strategy designed to solve this differences (inequalities). Although the efforts of increased income and the expansion of services are expected to traverse the rural population in different regions, poverty is still sever and pervasive in rural areas (MOFED 210 cited in Assefa Admasie Joachim Von Braun and Franz W. Gatzweiler).

It is important to note that the perception with regard to service provision and concomitant 
recourse mechanism is determined by the existence of reliance of the community on the government structure, and the existence and contribution of alternative private agents of service delivery at local and community levels. Following these general finding it is possible to answer the question of does service expanded after decentralization? But, strengthening of this finding by some quantitative data would be more useful, which is discussed below.

\subsection{Manova Analysis Result}

Multivariate analysis of variance (MANOVA) is an analysis of variance used when there are more than one dependent variable. Manova provides multivariate tests involving terms or linear combinations of the underlying design matrix. The four multivariate test statistics are Wilks' lambda, Pillai's trace, Lawley-Hotelling trace, and Roy's largest root.

Respondents were expected to evaluate the change (effect of decentralization) using leakert scale measured by the responses of very good, good, average, and poor. The analysis result reveals the positive effects of decentralization on service expansion, and improvement of skill. But, impact of decentralization on women empowerment was not the same as the other parameters used here; implies service in the woredas was better post decentralization. Details are given below.

Table 1. Effect of decentralization on service delivery: MANOVA result

\begin{tabular}{|c|c|c|c|c|c|c|c|c|}
\hline & \multicolumn{4}{|c|}{ Response from Administrators/servi } & \multicolumn{4}{|c|}{ Response from Community } \\
\hline No & Variable & Before & After & Difference & Variable & Before & After & Difference \\
\hline & Very good & 49 & 59 & 10 & Very good & 74 & 82 & 8 \\
\hline & Good & 61 & 152 & 91 & Good & 71 & 311 & 240 \\
\hline & Average & 198 & 109 & -86 & Average & 206 & 224 & 18 \\
\hline & Poor & 201 & 33 & -168 & Poor & 668 & 60 & -605 \\
\hline
\end{tabular}

The result is similar to that of the descriptive. It shows the progresses related to access to public services, which is indicated by the increasing of the total responses of good and very good, and reduction of average and poor.

- The computed value scored for the responses of good for both respondents (community and administrators) is highest count in post decentralization, which was 311 and 152 than before, which was 71 and 61 respectively. On the other hand a response related to poor for both (administrators and communities) has reduced from 201 to 33, and 668 to 60 respectively. But, responses related to average did not change much. From the analysis its clear that the perception gap between the community and the administrators about decentralization effect is higher. While the responses given by the administrators reduced from 198 to 109, community response has increased from 206 to 224.

The other key finding is the difference noticed between the rate of decreasing of percentage of responses of average and poor, and the rate of increasing of percentage of responses of very good and good, and it complements the above finding., While both show the changes the percentage of change is perceived differently. This finding is consistent to what has been discussed above and shows the variation (opinion difference) between the two respondents. 
Nevertheless, to both respondents the impact of decentralization on service delivery is evaluated as "good"

Multiple Analysis of Variance, or MANOVA, is an advanced form of the more basic analysis of variance, ANOVA. MANOVA extends the technique to studies with two or more related dependent variables while controlling for the correlations among them (www.//multivariate-statistical-analysis-). Therefore, for this type of study MANOVA helps to evaluate how each woredas performed based on the responses obtained to each of the questions posed about decentralization effect.

A manova for this study would allow multiple effects of decentralization-related outcome such as measuring its effect on service delivery, gender equality, and skill development. The statistical method is used to verify whether there is a variation in responses of the participants or not. Details were presented below.

Table 2. How did Administrators, and Communities Perceived Decentralization Effect

\begin{tabular}{|c|c|c|c|c|c|c|c|}
\hline \multicolumn{2}{|c|}{$\begin{array}{l}\text { W = Wilks' lambda } \\
\mathbf{P}=\text { Pillai's trace }\end{array}$} & \multicolumn{6}{|c|}{$\begin{array}{l}\mathbf{L}=\text { Lawley-Hotelling trace } \\
\mathbf{R}=\text { Roy's largest root }\end{array}$} \\
\hline Model & Source & Statistic & dff & F(df, & $d(\mathbf{f} 2)=$ & $\mathbf{F}$ & $\mid$ Prob $>$ F \\
\hline \multirow[t]{4}{*}{ Model } & $\mathrm{W}$ & 0.7276 & 4 & 20.0 & 597.9 & 3.01 & \begin{tabular}{|l|}
$0.000 \mathrm{a}$ \\
\end{tabular} \\
\hline & $\mathrm{P}$ & 0.2972 & & 20.0 & 732.0 & 2.94 & \begin{tabular}{|l|}
$0.000 \mathrm{a}$ \\
\end{tabular} \\
\hline & $\mathrm{L}$ & 0.3413 & & 20.0 & 714.0 & 3.05 & $0.000 \mathrm{a}$ \\
\hline & $\mathrm{R}$ & 0.2059 & & 5.0 & 183.0 & 7.54 & \begin{tabular}{|l|}
$0.000 \mathrm{u}$ \\
\end{tabular} \\
\hline Residual & \multicolumn{7}{|c|}{184} \\
\hline \multirow[t]{4}{*}{ Place } & $\mathrm{W}$ & 0.7744 & 3 & 15.0 & 497.3 & 3.22 & $0.000 \mathrm{a}$ \\
\hline & $\mathrm{P}$ & 0.2386 & & 15.0 & 546.0 & 3.15 & \begin{tabular}{|l|}
$0.000 \mathrm{a}$ \\
\end{tabular} \\
\hline & $\mathrm{L}$ & 0.2748 & & 15.0 & 536.0 & 3.27 & \begin{tabular}{|l|}
$0.000 \mathrm{a}$ \\
\end{tabular} \\
\hline & $\mathrm{R}$ & 0.1996 & & 5.0 & 182.0 & 7.27 & $0.000 \mathrm{u}$ \\
\hline \multirow{5}{*}{ Code } & W & 0.9385 & 1 & 5.0 & 180.0 & 2.36 & $0.0419 \mathrm{e}$ \\
\hline & $\mathrm{P}$ & 0.0615 & & 5.0 & 180.0 & 2.36 & $0.0419 \mathrm{e}$ \\
\hline & $\mathrm{L}$ & 0.0656 & & 5.0 & 180.0 & 2.36 & \begin{tabular}{|l|}
$0.0419 \mathrm{e}$ \\
\end{tabular} \\
\hline & $\mathrm{R}$ & 0.0656 & & 5.0 & 180.0 & 2.36 & \begin{tabular}{|l}
$0.0419 \mathrm{e}$ \\
\end{tabular} \\
\hline & Residual & 184 & & & & & \\
\hline Total & 188 & & & & & & \\
\hline
\end{tabular}

$\mathrm{e}=$ exact, $\mathrm{a}=$ approximate, $\mathrm{u}=$ upper bound on $\mathrm{F}$

Source: own computed

The first column of the table above gives the source (model). Place refers to the study woredas, and code stands for participants in the interview (administrators, and community representatives). Residual error is used for the denominator of the test. Four lines of output are presented for both, place and code, one line for each of the four multivariate tests, as indicated by the W, P, L, and R in the second column of the table.

The next column gives the multivariate statistics. Here Wilks' lambda for both ( place and code is 0.7744 and 0.9385 , Pillai's trace for both is 0.2386 and 0.0615 , the Lawley-Hotelling trace is 0.2748 and 0.0656 , and Roy's largest root for both place and code is 0.1996 and 0.0656 . Some authors report $\lambda 1$ and others report $\theta=\lambda 1 /(1+\lambda 1)$ for Roy's largest root. 
Stata reports $\lambda 1$.

The column labeled "df" gives the hypothesis degrees of freedom, the residual degrees of freedom, and the total degrees of freedom. These are just as they would be for an ANOVA. We have 3 and 1 degrees of freedom for the hypothesis. There are 184 residual degrees of freedom and 188 total degrees of freedom.

The next three columns are labeled " $F(\mathrm{df} 1, \mathrm{df} 2)=\mathrm{F}$ ", and for each of the four multivariate tests, the degrees of freedom and $\mathrm{F}$ statistic are listed. The following column gives the associated p-values for the F statistics. For place Wilks' lambda has an F statistic of 3.22 with 15 and 497.3 degrees of freedom, which produces a p-value small enough that 0.0000 is reported. And for code Wilks' lambda has an F statistic of 2.36 with 5 and 180 degrees of freedom with p-value 0.0419 reported. Likewise the F statistics and p-values for the other three multivariate tests follow for both place and code on the three lines after Wilks' lambda.

The final column indicates whether the F statistic is exactly $\mathrm{F}$ distributed, is approximately $\mathrm{F}$ distributed, or is an upper bound. The letters e, a, and $\mathrm{u}$ indicate these three possibilities, as described in the footer at the bottom of the table. For this example, the F statistics of place (and corresponding p-values) for Wilks' lambda, Pillai's trace, and the Lawley-Hotelling trace are approximate. The F statistic for Roy's largest root is an upper bound, which means that the p-value is a lower bound. Given all these values the Manova command above provides various statistics for testing whether the woreda, and communities means differ on any of the four dependent variables. These tests show that the positive effect of decentralization on the parameters but locals perception about its effect (magnitude of change) varies. There are significant differences between the respondents and in all the woredas related to decentralization effect on at least one of the dependent variables, which is indicated by the values of $F$ statistics and p-values.

The mvreg command also gives the actual coefficient estimates along with tests for each dependent variable separately. We performed mvreg which is equivalent to a factorial multivariate analysis of variance. It ensures that the main effects are estimated correctly (Multivariate Analysis, Multivariate Multiple Regression (http://www.philender.com (See Appendix 1).

Multivariate regression differs from multiple regressions in that several dependent variables are jointly regressed on the same independent variables. Multivariate regression is related to Zellner's seemingly unrelated regression (http://www.stata.com/manuals13/mvmvreg.pdf). The individual coefficients and standard errors produced by mvreg are identical to those that would be produced by regress estimating each equation separately. The difference is that mvreg, being a joint estimator, also estimates the between-equation covariance, so you can test coefficients across equations

From mvreg output it is clear that implication of decentralization on service deliver, building skill, and improving living condition is significant but its effect on women empowerment is minimal. This implies despite issues of gender is widely synchronized in each and every development frameworks there is an oversight and exaggeration about the agenda. 
Notwithstanding these strengths challenges are said to be numerous too and are effect of limited capacity at all levels of government, poor understanding, less commitments, and less accountability. During the time of data collection and focus group conducted with a group of women none were not able to give concrete evidence that verifies women are equal as men. Even if there are efforts to bring the gender inequality the existing social condition and lack of access to resource still led them to be disadvantageous. Gender and development policies and programs faces the danger of miss interpretation. The fact that women and men are equally albeit differently affected by development related problems must be highlighted.

To verify this model both, correlation matrix and Breusch-Pagan test was applied and the test confirms that the model is perfect fit. The second is applied for testing heteroscedasticity. A Breusch-Pagan test is a type of chi squared test. The Breusch -Pagan test is significant, so the residuals of these five space variables are not independent of each other. The variation in responses by the respondents could be due to the responsibility that they have, or due to the suspicion that they feel while requested they tried to exaggerate the over all changes obtained related to service expansions (see appendix 2).

Over all based on the data and the analysis it can be said that to some extent outlawing centralization has enhanced public service expansions in small administrative unit of the rural woredas of Tigrai. Confirms introduction of fiscal decentralization helped to change the development of the periphery without which it would not have been realized. However, effect of decentralization on improving quality of life and reducing inequality is still questioned. Despite the undergoing growth institutional changes failed to address the problem of inequality in between the genders. There was an instance were number of women in all the study woreda from the community complain about the unfair implementation of land laws, divorce, and separation. There are positive indications that women are permitted greater voice and have more awareness of their basic rights. At the same time slower change is occurring in the reciprocal engagement by public officials in this opening up of society... the attitudes of officials on land law, property right, and divorce tend toward the unresponsive. Promoting pro-poor growth requires a strategy that is deliberately biased the specific groups (the poorer).

\subsection{Impact of Decentralization on Public Service Expansion and Welfare (Graphical Depiction)}

In order to explain how decentralization effect to expansion of public services, improving efficiency, and contributes to the rising of wellbeing the following assumption were set.

1. Pre-decentralization public service facilities in the rural woreda of Tigray was very poor.

2. Availability of public services, or increasing of skill, or improving public participation contributes to the increasing of productivity.

3. In any stable economy, and in a normal situation any institutional or administrative change has a positive effect on income

4. Service expansion converges to income. 


\section{Macrothink}

Journal of Public Administration and Governance

ISSN 2161-7104

2017, Vol. 7, No. 4

Given these presumption over all gain and/or loss of decentralization effect on income (nexus) was presented by the figure below.

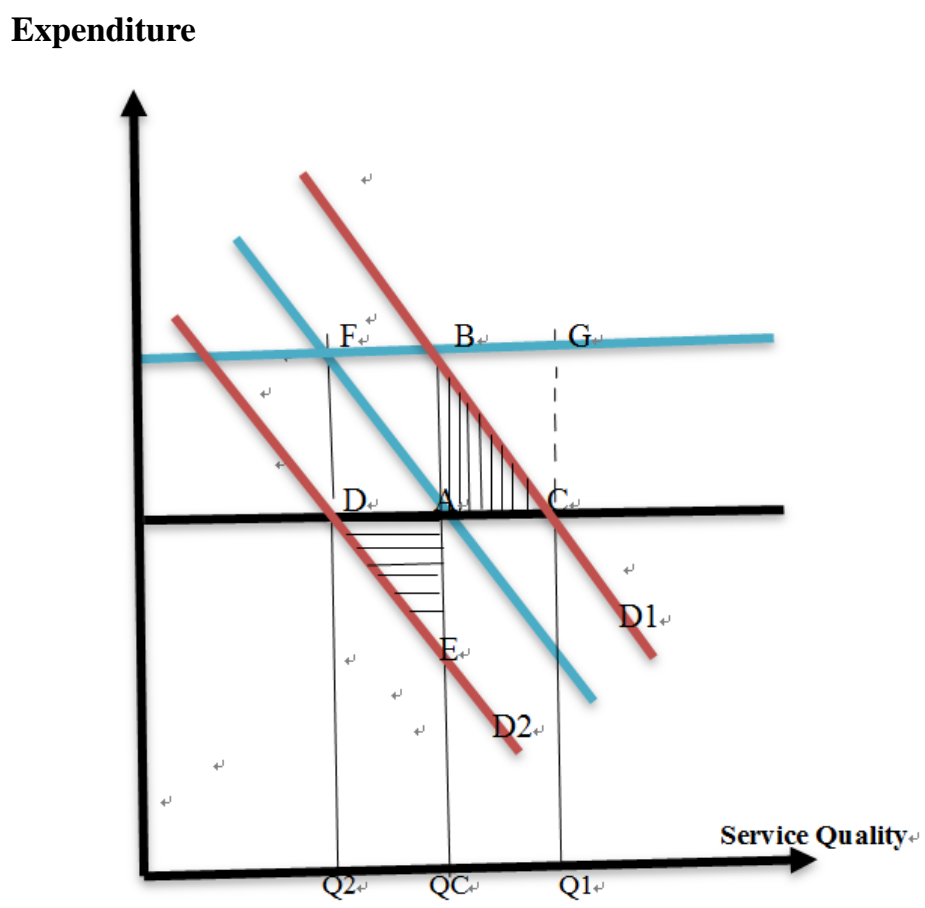

Figure 2. The Trade-off Between Centralization and Decentralization

Improving standard of living in this context was anticipated to occur as a result of increasing in income, which was expected to appear in return to the expansion of public services; contemplating the theory of service expansion converges. Different writers (Ashenfelter and Rouse (2000), Heckman (2005)) discussed the effect of schooling on income, and decreasing of inequalities.

On the fig above Qc is the quantity of public services provided under centralization system, which is lower than the amount demanded by the locals; (1), but more than what demanded by the representative individual (2). As a consequence (following centralization policy) each of these individuals would experience income losses of ABC (a loss that could have been minimized through implementing decentralization) and ADE (actual loss occurred following centralization). The first (ABC) is loss caused by the individual not having income as much as they should if area one could decide on the amount of the good to be provided (area one in this is nothing but decentralized government). Individual A is willing to pay QcBCQ1 to get QCQ1 even though these would only cost QCACQ1 to be available. Similarly triangle ADE losses experienced by individual 2 because he is consuming more than he would otherwise choose, paying Q2DAQC for consuming Q2Qc while valuing them at only Q2DEQc, implies income loss in this case stated as welfare deadweight lose from centralization are greater if heterogeneity greater.

All these shows the interdependent between institutional system and service delivery, service delivery and income, and income effect on welfare. Taking the given presumptions into consideration decentralization can minimize dead weight losses as a result of addressing the 
heterogeneity differences. The figure shows the increasing of income which is similar to welfare (service expansion) by the area of AFD and ADE overcoming the losses that could occur when centralization system was implemented. Offsetting the differences in preference and empowering local administrators enables not only to solve the loss of welfare given by the area of $\mathrm{ADE}$ and $\mathrm{ABC}$ but could also help to the maximizing of welfare more than what is gained.

Our argument in here is the implementation of decentralization system has helped. However, we also learned about the existed challenges were small administrative units in Ethiopia are facing. This confirms that if the institutional system (decentralization) in the study woredas was not challenged by the stated problems its effect on welfare could have been the area of FGDC and AED (the total area of AFD+ ABF+AED+ABC+BGC). Writers believe that in spite of the current achievement the existed limitations are still affecting decentralization impact, which led welfare gains of decentralization to be far lower than expected. On the figure the total area of $\mathrm{ABF}+\mathrm{BGC}$ is a welfare loss even after decentralization. This was confirmed during the survey; administrator repeatedly mentioned about the technical and skill gaps they are facing while designing plan, implementing development programs, or policies. Lack of technical efficiency hindered decentralization impacts on rural development. Practically there are no more firms or businesses owned by the individual that could help to rise the revenue collected by the woreda but still the capacity to collect from the existed is very poor. Therefore by implementing decentralization the total gain achieved is $A E D+A F D+A B C$. Due to the existed challenges the total welfare loss at present is believed to be $\mathrm{ABF}+\mathrm{BGC}$.

Outlawing centralization in Ethiopia helped to the emergence of civil society organizations, assisting to the transformation of the country economic and political arena. This confirms decentralized provision of public goods and services to be pareto-superior to centralized determination of public outputs.

Investing on public services to defend the prevalent poverty that exists within the communities is necessary. It is recognized as very important areas of development were the productivity gains are attributable to better allocation of resources and to economies of scale, which comes not only due to change in system but is mainly due to changing perception and building capacity.

\subsection{Conclusion}

This study tried to investigate the implication decentralization on service expansion of Tigray. Finding reveals the positive changes; service facilities increased from extremely low to somewhat reasonable level.

This study presented how service expansion impacted the wellbeing of the community. Result shows impact of access to services, and its relationship with improving quality of life. The same is also with the availability of education. Education helped to the increasing of individual's participation in productivity, and encouraged farmers to diversify their economic activity. This effect to empower locals, enhanced communication for development, and 
increased public service expansion according to their priority needs and preferences of the grass root level. ${ }^{13}$ Likewise access to water point had helped people to reduce the distance they were traveling to get drinking water. This mainly helped women as in rural area of Ethiopia water fetching is exclusively the main chore of women and children. On the other hand access to road has helped rural areas to get networked and it enhanced the market interaction and exchange.

Implication of decentralization in reducing gender gap and inequality still requires further effort. This is confirmed from the result of the statistical analysis. While initiatives made so far are quite encouraging its practical impact in reducing gender inequality is not still in the form of one to one.

Thus, its quite clear that decentralization has helped to have some gains. But, the first major argument against decentralization is diseconomies of scale. Implementation of development programs may not be better if local administrators are ordering their needs ahead of the citizens, when public resource is not efficiently used and decentralization is complemented by corruption and nepotism.

Decentralization may not be effective if locals are not having the required skill and knowledge. This may undermine the competence of local bodies to plan, coordinate, and execute the new tasks (Asante, 2003; in van Dijk and Tegegne, 2005). This problem can further be complicated if there is lack of clearly defined accountability, and responsibility between and within different actors at the central, regional, and local levels (Arun and Ribot, 1999).

Moreover, local bodies may not necessarily reflect the interests and developmental priorities of the community they represent. It is imputed that local elites and dominant individuals may hijack the decentralized power and authority to pursue their own interests and may not promote efficiency and equity (Collins, 1989; Mills et al., 1990).

This problem is common but it mainly weighs on the issue of gender were most women with power or responsibility often assume as if women related problem in Tigray is $100 \%$ solved assuming that their gain is every women gain. This feeling makes the topic of gender more complex and identifying the core problem became so hard as problem are still masked.

One of the major challenges mentioned in all the study woredas is corruption, decentralization enhanced corruption. ${ }^{14}$ Previous studies also shown that the level of corruption at local governments can be much higher than at the central level (Brueckner, 1999; Dethier, 2000 von Braun and Grote, 2000). The problem can be more severe if the

\footnotetext{
${ }^{13}$ DLDP enhanced Community responsibility; community are contributing labor and local materials to construct services like education, health, farmers training center, and water point.

${ }^{14}$ Corruption is defined as exercise of official powers against public interest or the abuse of public office for private gains. Public sector corruption is a symptom of failed governance. Here, we define "governance" as the norms, traditions and institutions by which power and authority in a country is exercised-including the institutions of participation and accountability in governance and mechanisms of citizens' voice and exit and norms and networks of civic engagement; the constitutional-legal framework and the nature of accountability relationship among citizens and governments (Shah, A. 2006).
} 
expected participation of the community cannot be materialized.

\section{Reference}

And.ré, P., \& Dieudonné, B. (2001). Development of a conceptual and methodological framework. (http://www.ceaaacee.gc.ca/015/0002/0015/index_e.htm).

Arun, \& Ribot. (1999). Fiscal decentralization and public service delivery in South Africa. Working paper, No. 19.

Asfaw, A., Frohberg, K. James, S., \& Jütting, J. (2004). Modeling the impact of fiscal decentralization on health outcomes: Empirical evidence from India. ZEF Discussion paper on development policy, No.87.

Ayele, Z. (2011). Local government in Ethiopia: Still an apparatus of control? Journal of Law and Democracy, 15, ISSN 2077-4907.

Besley, T. (1997). Political economy of alleviating poverty: Theory and institutions. In: M.Bruno, B. Pleskovic. ABCDE 1996. The World Bank, Washington DC.

Bird, R. M. (1993). Threading the fiscal labyrinth: Some issues in fiscal decentralization, National Tax Journal, 46(3), 207-227.

Braun, J., \& Grote, U. (2000). Does Decentralization serve the poor? Center for development research (ZEF-Bonn) University of Bonn, Germany, 20-21 November, Washington D.C.

Brueckner, J. (1999). Fiscal decentralization in LDCs: The effects of local corruption and tax evasion. Mimeo, Department of Economics, University of Illinois at Urbana-Champaign.

Building Department, Good Governance and Peace Building Division (DMV/VG).

Collins, C. D. (1989). Decentralization and the need for political and critical analysis, Health Policy and Planning, 48, 168-169. https://doi.org/10.1093/heapol/4.2.168

Dethier, J. (ed.). (2000). Governance, decentralization and reform in China, India and Russia. Kluwer Academic Publishers and ZEF.

Diamond, Larry, \& Svetlana, T. (1999). Size and democracy. The case for decentralization. In Developing democracy. Toward consolidation, ed. L. Diamond. Baltimore and London: The Johns Hopkins University Press, 117-60.

DLDP review, PPA, CIDA cited in Dom and Mussa. (2006). Review of Implementation of the Decentralization Policy: A Sample Survey in Four Sentinel Woredas of Tigray Region.

Eaton, K. (2001). Political obstacles to decentralization: Evidence from Argentina and the Philippines, Development and Change, 32, 101-127. https://doi.org/10.1111/1467-7660.00198

Falleti, T. G. (2005). A Sequential Theory of decentralization: Latin American cases in comparative perspective. The American Political Science Review, 99(3), 327-346. https://doi.org/10.1017/S0003055405051695 
Garmendia, B. C., Estache, A., \& Shafik, N. (2004). Infrastructure services in Developing Countries: Access, quality, costs, and policy reform, World Bank Policy Research Paper, 3468 .

Hertogs, E. J. (1999). What role for local authority in decentralized cooperation under convention of Lome, ECDPM discussion paper No. 8 cited in Tewodros, B.2005.

IMF. (1999). Republic of Moldova: Recent economic developments, IMF staff country report, 99/110.

Impact assessment of decentralized basic service delivery in Ethiopia. (2013). Document of the World Bank, Report No: 84215-ET, Social protection Sector, country department AFCE3, Africa Region.

Jumadi, M. P., Ghozali, M., \& Moh, K. (2013). The impact of fiscal decentralization on local economic development in East Java, OSR Journal of Humanities and Social Science (IOSR-JHSS), 13(1). (Jul. - Aug. 2013).

Local Development International. (2013). The Role of decentralization/Devolution in improving development outcomes at the local level: Review of the literature and selected cases, UK Department for International Development South Asia Research Hub, Brooklyn, New York. USA.

Manor, J. (1999). The political economy of democratic decentralization. Washington, DC: The World Bank cited in G. Falleti, T. 2005. A Sequential theory of decentralization: Latin American cases in comparative perspective, The American Political Science Review, 99(3) (Aug., 2005), 327-346).

Martinez, V. J. (2001). Impact of fiscal decentralization, issues in theory and challenges in practices, ADB Publication.

Martinez, V. J., \& Robert, M. M. (2000). Fiscal decentralization and economic growth, International studies program, Andre young school of policy studies. Georgia State University. Working Paper, 01.

Mills, A. J. P., \& Vaughan, D. S. (1990). Health system decentralization: concepts, issues and country experiences. World Health Organization; Geneva.

Mogues, T. et al. (2009). The governance of service delivery for the poor and women: A Study of rural water supply in Ethiopia, Development strategy and governance division, International food policy research institute - Ethiopia strategy support program 2, Ethiopia.

Ndegwa, S. (2002). Decentralization in Africa, A Stocktaking survey, Africa region. Working paper series No.40, World Bank Washington.

Netherlands Ministry of Foreign Affairs. (2002). Decentralization and local governance from the perspective of Poverty Reduction, Human Rights, Humanitarian Aid and Peace

Noll, H. (2002). Social indicators and quality of life research: background, achievements and current trends, Published in: Genov, Nicolai Ed. (2002) Advances in sociological knowledge 
over half a century. Paris: International Social Science Council.

Oates, W. (1993). Fiscal decentralization and economic development, National Tax Journal, 46, 237-243.

Piter V., \& Tegegne, G. (2005). Issues and challenges in local and regional development, Decentralisation, urban services and inequality. Addis Ababa: University RLDS,

Pokharel, B. (2000). Decentralization of health services. WHO Project: ICP OSD 001, World Health Organization, Regional office for South-East Asia, New Delhi.

Shah, A. (2006). Corruption and decentralized public governance in Anwar Shah, World Bank. https://doi.org/10.1596/1813-9450-3824

Sintayoh, F., Meheret, B., \& Mathijs, E. (2013). Decentralization as an institutional system, prospects and retrospect: Case of Four Weredas of Tigray, Presented in a regional conference, Published in a proceeding of the Ethiopian Economic Association.

Smoke, P. (2001). Fiscal decentralisation in Developing Countries: A Review of current concepts and practice, Democracy, Governance and Human Rights Programme Paper No. 2, UNRISD, Geneva.

Snyder, R. (2001). Scaling Down: The subnational comparative method. Studies in comparative international development, 36(1), 93-110. https://doi.org/10.1007/BF02687586

Steinich, M. (2002). Monitoring and evaluating support to decentralization, challenges and dilemmas, a seminar paper on "European support for democratic decentralization and municipal development- A contribution to local development and poverty reeducation, held in Maastricht, 14-15 organized by ECDPM and Swedish Ministry of Foreign Affairs.

Stiglitz, J. E. (2010). Report by the commission on the measurement of economic performance and social progress.

Tanzi, V. (2000). Some Politically Incorrect Remarks on Decentralization and Public Finance. In: Dethier, Jean-Jacques (ed.) (2000), Governance, Decentralization and Reform in China, India and Russia. Kluwer Academic Publishers and ZEF, 47-64.

Tegegne, G., \& Kassahun, B. (2004). The Role of Decentralized Governance in Building Local Institution, Diffusing Ethnic Conflicts and Alleviating Poverty in Ethiopia (eds) in Local Governance and Poverty Alleviating in Africa, Regional Development Dialogue, 25(1), United Nations Center for Regional Development, Nagoya, Japan.

Tesfay, T. (2006). Decentralization and Service Delivery in Ethiopia: A Case of Moretenna-Girr and Bereh Aletu Woredas in Amhara and Oromia (Regions Respectively), MA Thesis, RLDs/AAU, Addis Ababa.

Tewdros, B. (2005). Decentralization Development Cooperation, Governance and Rural Livelihood: The case of Amhara region, Ethiopia in Issues and Challenges in Local and Regional Development, Tegegne g., and Pitter Van Dijk, P. 2005 (Edi.). 


\section{Macrothink}

Journal of Public Administration and Governance

ISSN 2161-7104 2017, Vol. 7, No. 4

Turner, M., \& David, H. (1997). Governance, Administration and Development; Making the state work, New York, Palgrave. https://doi.org/10.1007/978-1-349-25675-4

Von Braun, J., \& Grote, U. (2000). Does Decentralization Serve the Poor? Center for Development Research (ZEF-Bonn) University of Bonn, Germany.

\section{Appendix 1}

\begin{tabular}{|c|c|c|c|c|c|c|}
\hline Equation & Obs & Parms & RMSE & "R-sq" & $\mathrm{F}$ & $\mathrm{P}$ \\
\hline ubs & 189 & 3 & .82696 & 0.0108 & 1.011063 & 0.0358 \\
\hline 1сараaba & 189 & 3 & .7505533 & 0.0400 & 3.872899 & 0.0225 \\
\hline shotraina & 189 & 3 & .6498454 & 0.0158 & 1.494092 & 0.2271 \\
\hline livina & 189 & 3 & .7870433 & 0.0527 & 5.177543 & 0.0065 \\
\hline womempoa & 189 & 3 & .6954257 & 0.0094 & .8803291 & 0.4164 \\
\hline
\end{tabular}

\begin{tabular}{|c|c|c|c|c|c|c|}
\hline & | Coef. & Std. Err. & $\mathrm{t}$ & $P>|t|$ & \multicolumn{2}{|c|}{ [95\% Conf. Interval] } \\
\hline \multicolumn{7}{|l|}{ pubserva } \\
\hline place & .0737197 & .0537513 & 1.37 & 0.072 & -.0323209 & .1797602 \\
\hline code & .0446446 & .1271278 & 0.35 & 0.726 & -.2061531 & .2954422 \\
\hline _cons & 2.182767 & .1108486 & 19.69 & 0.000 & 1.964084 & 2.401449 \\
\hline \multicolumn{7}{|l|}{ icapaba } \\
\hline place & .1339992 & .0487848 & 2.75 & 0.007 & .0377564 & .2302419 \\
\hline code & .0461053 & .1153815 & 0.40 & 0.060 & -.1815194 & .27373 \\
\hline _cons & 1.586177 & .1006065 & 15.77 & 0.000 & 1.387701 & 1.784654 \\
\hline \multicolumn{7}{|l|}{ shotraina } \\
\hline place | & -.0089022 & .042239 & -0.21 & 0.833 & -.0922312 & .0744269 \\
\hline code & -.171 & .0998999 & -1.71 & 0.089 & -.3680824 & .0260824 \\
\hline _cons $\mid$ & 2.325674 & .0871073 & 26.70 & 0.000 & 2.153828 & 2.497519 \\
\hline \multicolumn{7}{|l|}{ livina } \\
\hline place $\mid$ & -.0664789 & .0511566 & -1.30 & 0.095 & -.1674007 & .0344429 \\
\hline code & -.3533246 & .1209911 & -2.92 & 0.004 & -.5920158 & -.1146333 \\
\hline _cons & 2.630112 & .1054978 & 24.93 & 0.000 & 2.421986 & 2.838238 \\
\hline \multicolumn{7}{|l|}{ womempoa } \\
\hline place & .0599125 & .0452016 & 1.33 & 0.187 & -.0292613 & .1490862 \\
\hline code & -.0091488 & .1069069 & -0.09 & 0.932 & -.2200547 & 201757 \\
\hline _cons & 1.523974 & .093217 & 16.35 & 0.000 & 1.340076 & 1.707873 \\
\hline
\end{tabular}

Source: own computed

\section{Appendix 2}

Correlation matrix of residuals:

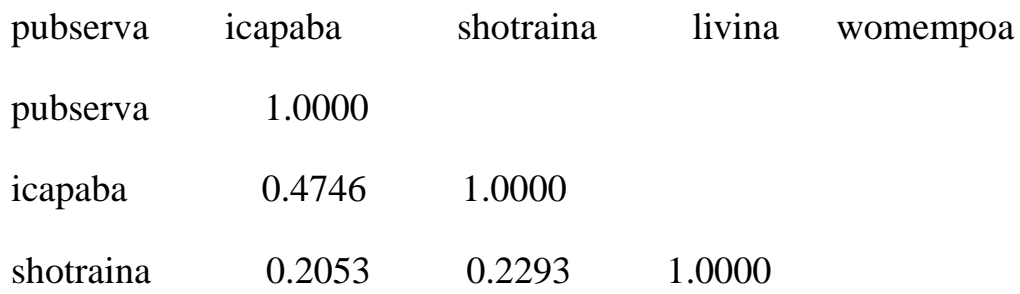


livina

0.2300

0.2508

0.2388

1.0000

womempoa

0.4091

0.3833

0.1620

0.1825

1.0000

Source: own computed

\section{Copyright Disclaimer}

Copyright for this article is retained by the author(s), with first publication rights granted to the journal.

This is an open-access article distributed under the terms and conditions of the Creative Commons Attribution license (http://creativecommons.org/licenses/by/4.0/). 